\title{
Combining Forces: The South African Sign Language Bible Translation Project
}

\author{
Ananda Van der Walt ${ }^{1}$ \\ Hands with Words, Cape Town, South Africa \\ E-mail: anandavdwalt@gmail.com \\ Banie Van der Walt \\ Hands with Words, Cape Town, South Africa \\ E-mail: banievdwalt@gmail.com \\ Myriam Vermeerbergen \\ KU Leuven, Belgium and Stellenbosch University, South Africa \\ E-mail: myriam.vermeerbergen@kuleuven.be
}

\begin{abstract}
This paper reports on the South African Sign Language Bible Translation Project, an ongoing project aiming to translate 110 Bible stories into South African Sign Language (SASL). The project started in 2014 and, at the time of writing, 32 stories have been finalised. A team of three Deaf ${ }^{2}$ signers are translating the stories from written English to SASL. As signed languages have no written form, the signed translations are video-recorded. The Deaf translators are working with exegetical assistants, a Bible translation consultant with expertise in signed language (Bible) translations, a signed language interpreter who facilitates the communication between the Deaf translators and hearing collaborators, and an editor. Back translations are done by both Deaf and hearing collaborators who are proficient in SASL and English. The Deaf community of South Africa assists the Deaf translators with signs for Biblical names and terms when required.
\end{abstract}

This paper documents the modus operandi of the team as a sequence of different steps. We focus on the many challenges involved in this process, specifically those related to working between the written form of a spoken language (English) and a visual-gestural language with no written form (SASL) and only a short history of institutionalisation.

\footnotetext{
1 Ananda and Banie Van der Walt are both members of the SASL Bible Translation Project team; Myriam Vermeerbergen is a sign language linguist and sign language interpreter trainer.

${ }^{2}$ In the literature in the fields of Signed Language Linguistics, Deaf Education, Deaf Studies, etc., the capital D is sometimes used to refer to people or organisations that self-identify as "culturally Deaf". This allows for the differentiation between "deaf", which most often refers to the hearing status, and "Deaf", referring to a sociocultural (and linguistic) identity. In view of the importance of self-identification, we have decided to only use capital D in this paper to refer to people and organisations when we know for certain that they self-identify as "Deaf"; in all other cases, we use "deaf".
} 
Keywords: signed language translation; Bible translation; South African Sign Language; South African Deaf Community

\section{Introduction}

Because of their hearing loss, deaf people's access to spoken language(s) is limited. For prelingual deaf children, this limited accessibility makes it very difficult to acquire a spoken language. This is one, but not the only, reason why most prelingual deaf people use a signed language as their preferred language. However, as signed languages do not have an established written form, deaf learners - even those learners taught mainly in a signed language - face the challenge of learning to read and write (in) a non-signed language. A wide range of international studies reports low literacy levels among students with prelingual deafness (e.g. Marshark 1997; Lederberg, Schick and Spencer 2013; Hrastinski and Wilbur 2016). This is, in part, due to the discrepancy between these students' incomplete spoken language system and the demands of reading a speech-based system (Perfetti and Sandak 2000, in Geers and Hayes 2011). In South Africa, the average deaf school-leaver is said to have a written language comprehension ability equal to that of an 8-year-old hearing child, and as few as one out of three deaf adults is functionally literate (Glaser and van Pletzen 2012, referring to Aarons and Glazer 2003 and DeafSA 2009).

The signed language used by the South African Deaf community is known as South African Sign Language (SASL). Approximately $95 \%$ of deaf children, worldwide and in South Africa, come from hearing families who use a spoken language or several spoken languages, and are often not (or only to a limited extent) able to sign (Mitchell and Karchmer 2004). Furthermore, as is the case for "hearing schools", English is the dominant spoken/written language of learning and teaching in many South African deaf schools. This situation implies that the majority of deaf South African children grow up with at least three languages - one signed and two spoken - that they learn and use for different purposes and that are usually mastered at different levels (Glaser and van Pletzen 2012).

Because of the challenges many deaf people face when reading, steps have been taken to make the written Bible more accessible for deaf readers, and specific versions for deaf audiences have been developed. One example is The Holy Bible: English Version for the Deaf (Baker 1987). For South Africa, we know of at least one English Bible for the Deaf ${ }^{3}$ - and there is also the Afrikaans Bybel vir Dowes (ABD), now called the Bybel vir Almal (Bible Society of South Africa 2008). ${ }^{4}$ Van den Heever (2003, in Lombaard and Naudé 2007) discusses how, for the $\mathrm{ABD}$, the Afrikaans language was adapted to suit the needs of deaf readers, e.g. complex sentences were avoided, and class nouns such as rivier ('river') or berg ('mountain') were added to geographical names to assist the deaf reader in identifying the referent.

As previously noted, signed languages do not have a written form, but the advent of digitised video-recordings, computer technology, and software development has made it possible to

\footnotetext{
3 The Bible for the Deaf was published by the Bible Society of South Africa in November 2019 (www.biblesociety.co.za).

${ }^{4}$ Bybel vir Almal was first published as Bybel vir Dowes. However, this version of the Bible became very popular, not only within the Deaf community, but also with hearing people who found it easy to understand. This is why it was decided to change the name to Bybel vir Almal (www.nid.org.za/bybel-vir-dowes).
} 
produce "signed texts", i.e. video-recorded narratives in a signed language. This means that it has also become possible to create a signed Bible. A small-scale study done by Susan Lombaard in 2003 shows that "biblical texts in South African Sign Language [...] are more accessible than written or printed biblical texts for deaf-born South African people who use sign language as their first language" (Lombaard and Naudé 2007: 141). Within the framework of this 2003 study, six parts of the Bible - three extracts from the Old Testament and three from the New Testament - were translated into SASL by a team comprising six deaf native signers and a hearing sign language interpreter. The video-recorded translations were used for an empirical study involving 77 deaf participants from five different South African provinces. Each participant read the written versions of three of the six extracts and looked at the signed translation for the three other extracts. Comprehension of the six texts was tested by a set of questions asked and answered in SASL. Lombaard and Naudé (2007: 151) concluded that:

religious information in written format is generally inaccessible to the Deaf community of South Africa. To address this problem, a Bible in SASL is needed. Translation, however, is a very specialised process and skilled people are needed to coordinate the process. As sign language is the first language of deaf-born people, it is of the utmost importance that they form part of the translation team as well as the production team of such a video. A Bible in SASL will ensure that the Scriptures are made accessible to a minority group that has been deprived of rights for so many years.

This paper reports on the current South African Sign Language Bible Translation Project. The project aims to translate 110 Bible stories from written English to video-recorded SASL. The work started in 2014 and, at the time of writing, the first set of 32 stories has been approved and published electronically (see https://deaf.bible/ZACBT/god-creates-everything/intro). The project team consists of three Deaf signers - Agnes Kunene, Richard Kunene, and Matthew Manake - collaborating with (i) exegetical assistants (EAs) who have Biblical/theological knowledge as well as knowledge of the source languages Greek and Hebrew, (ii) a Bible translation consultant with expertise in signed language (Bible) translations, also knowing the source languages and at least one signed language, (iii) a SASL interpreter who facilitates the communication between the Deaf translators and hearing collaborators, and (iv) an editor. The Deaf community of South Africa is assisting the Deaf translators with signs for Biblical names and terms when required.

Section 3 of this paper documents the modus operandi of the team as a sequence of different steps. Section 4 focuses on the many challenges involved in this process, specifically those challenges related to working between the written form of a spoken language (English) and a visual-gestural language with no written form (SASL) and only a short history of institutionalisation. Section 5, the concluding section, links the experiences of the project members to the literature on aspects of signed language interpreting and translating. In the next section, we first introduce signed languages in general, and SASL in particular.

\section{Introducing signed languages}

Natural human languages come in two forms: spoken languages and the less well-known signed languages. Signed languages are the visual-gestural languages of Deaf communities and are not universal - they differ from country to country and sometimes even from region to region. A signed language is not some kind of "manual rendering of a spoken language"; signed languages 
are independent from spoken languages, as is evidenced by the fact that countries which share a spoken language - e.g. English in England, Ireland, and the US - may each have their own national signed language. Equally, in multilingual countries such as South Africa, there may be many different spoken languages but only one signed language.

Modality is a significant difference between signed and spoken languages. While spoken languages are received and expressed via the auditory-vocal channels, signers make use of their hands but also their head, face, and torso to express themselves in three-dimensional space (Vermeerbergen, Leeson and Crasborn 2007). Research has clearly shown that signed and spoken languages share fundamental properties at all levels of linguistic structure, but it has also revealed that modality plays a role in shaping linguistic structures and mechanisms (Perniss, Pfau and Steinbach 2007). The fact that signed languages are expressed in space, making use of manual and non-manual articulators, gives rise to a high degree of simultaneity of articulation and visual imagery. Such modality-specific properties contribute to a certain degree of similarity across signed languages (Vemeerbergen 2006, Vermeerbergen and Van Herreweghe 2010).

The use of space is an important characteristic of all signed languages studied to date and can be seen, for example, in referent tracking. When a referent is physically present, a signer will typically point to the location where the referent is situated. When the referent is absent, the signer can "establish a locus", i.e. associate a certain area in the signing space with the absent referent. Establishing a locus can be done by pointing at such an area immediately before, after, or simultaneously while producing one or more signs identifying the referent, e.g. producing the sign MOTHER ${ }^{5}$ with the dominant hand whilst pointing at a certain area in the signing space with the other hand. The choice of a locus is frequently motivated. For instance, a signer may refer to an absent family member by pointing towards his/her chair. When there is a difference in status between referents, a signer typically associates a locus higher in the signing space for the highest-ranking referent. By pointing towards a previously established locus, the signer tracks referents across the discourse (Vermeerbergen and Leeson 2011).

In many signed languages, loci may also be used in verb agreement. Some verbs allow for alteration of the direction of their movement in order to reflect changes in their argument structure. The South African sign TO-VISIT, for example, can be signed with a movement starting from the agent's locus towards the patient's locus. This means that in order to express the meaning "I visit X", the verb sign TO-VISIT may be produced with a movement away from the signer's body (see Figure 1), whereas for "X/you visits/visit me", the articulation of TOVISIT often involves a movement towards the signer's body (see Figure 2).

\footnotetext{
${ }^{5}$ Signs are "written" here with English glosses, i.e. English words representing the meaning of the sign as closely as possible. MOTHER is the gloss for the SASL sign meaning "mother" and TO-VISIT is the gloss for the (single) sign meaning "to visit".
} 

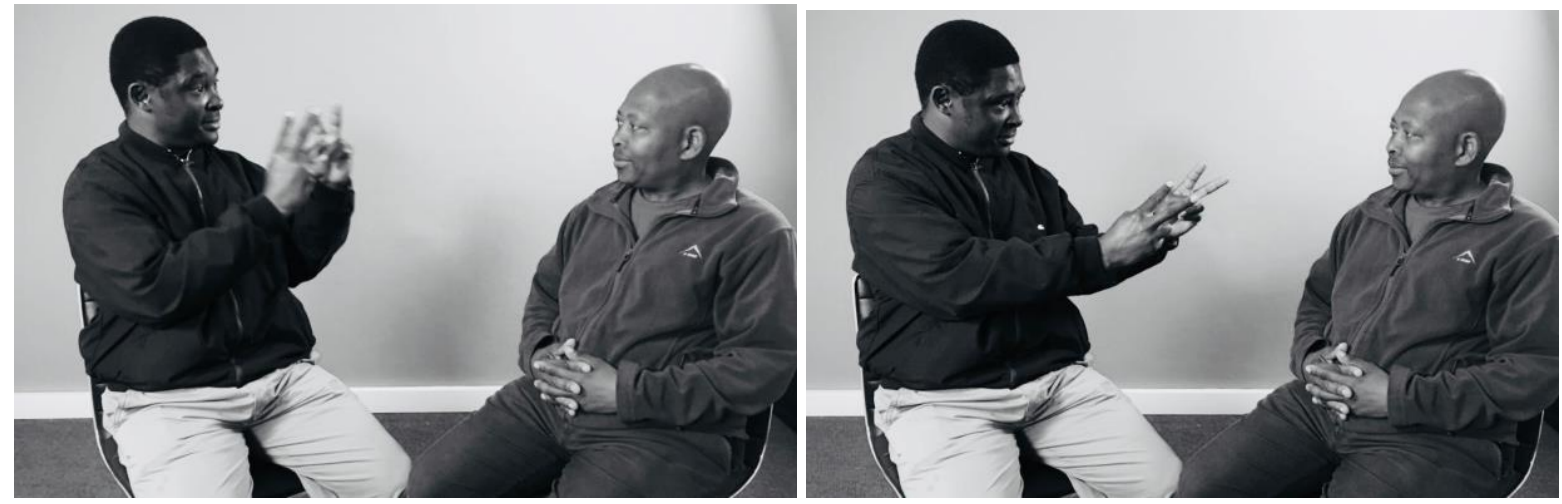

Figure 1. SASL verb sign TO-VISIT showing agreement to mean "I visit you"
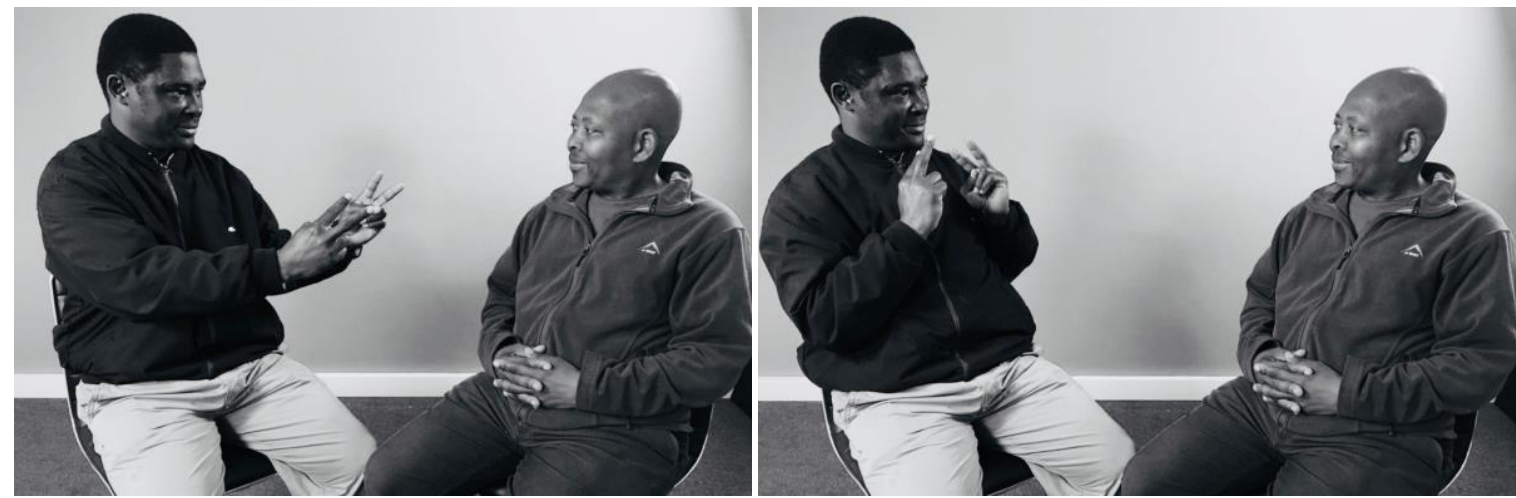

Figure 2. SASL verb sign TO-VISIT showing agreement to mean "you visit me"

In signed languages, space may also be used to represent space, and motion can be used to express motion. In Figure 3 below, taken from a short picture story in SASL, the signer's left hand represents a car driving through a tunnel.

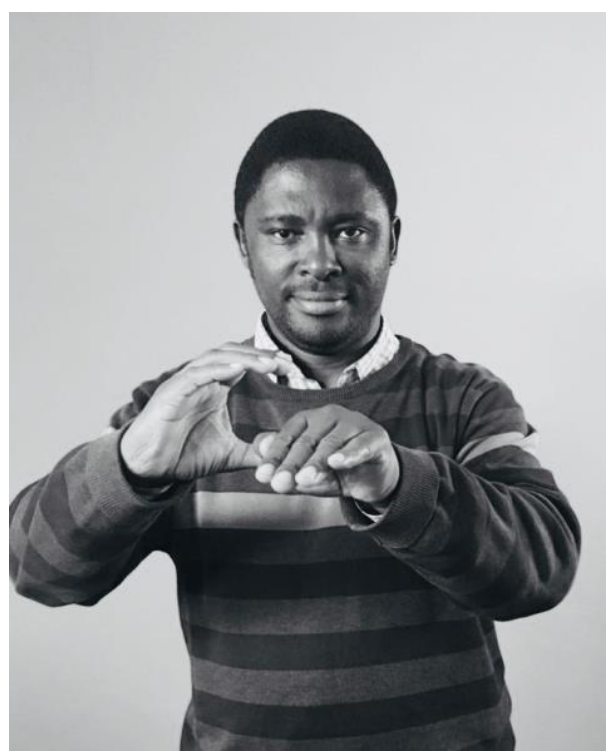

Figure 3. Productive sign with the left hand referring to a car and the right hand referring to a tunnel

As can be seen from these and similar examples, information about what an object looks like, the manner in which it moves or is moved and/or how it is handled is often overtly coded in a 
signed language. As we will discuss further in this paper, this is a challenge for interpreters and translators working from a spoken language to a signed language, as this information is not typically expressed in the spoken source language.

Whereas iconicity also exists in spoken languages - e.g. in onomatopoeia, intonation, sound symbolism, and so on - it is clear that the enormous potentiality of the visual-gestural signal for iconic motivation, and specifically for image iconicity, is a modality consequence (Demey, Van Herreweghe and Vermeerbergen 2008). In the domain of iconicity - or visual imagery - we do, however, see an overlap between signed languages and (co-speech) gesture. A clear example is "constructed action", also called "enactment", i.e. the narrator's construction of another person's actions (Metzger 1995), which seems to be similar in signed languages and in gesture (Liddell and Metzger 1998). A number of researchers argue that when the communication of signers and speakers is being compared, it is speech in combination with (co-speech) gesture - and not speech by itself - that constitutes the appropriate level for cross-linguistic analysis (see e.g. Enfield 2004; Taub, Pinar and Galvan 2002; Vermeerbergen and Demey 2007).

Another interesting characteristic of signed languages is the importance of the productive lexicon. The lexicon of signed languages consists of the established and the productive lexicon. Established signs, also simply called "lexical signs", are highly conventionalised signs in both form and meaning, and can easily be listed in a dictionary. Brennan (1992: 45-46) describes them as "ready-made, off the shelf lexical items. They are already in existence: the signer simply has to pluck them from her/his mental lexicon and place them in the appropriate lexical context". In contrast, productive signs are the result of a process which "involves selecting the component parts and putting them together in appropriate ways to create particular kinds of effects" (Brennan 1990: 163). Productive signs are normally not included in dictionaries. In Figure 3 above, the left hand of the signer produces a classifier handshape and refers to a driving car. The signer does not use the SASL lexical sign TO-DRIVE (see Figure 4) but expresses the movement of the car in a more productive, visual way. Rather than simply "saying" what is happening, the signer here chooses to "show" (cf. Cuxac 2000).

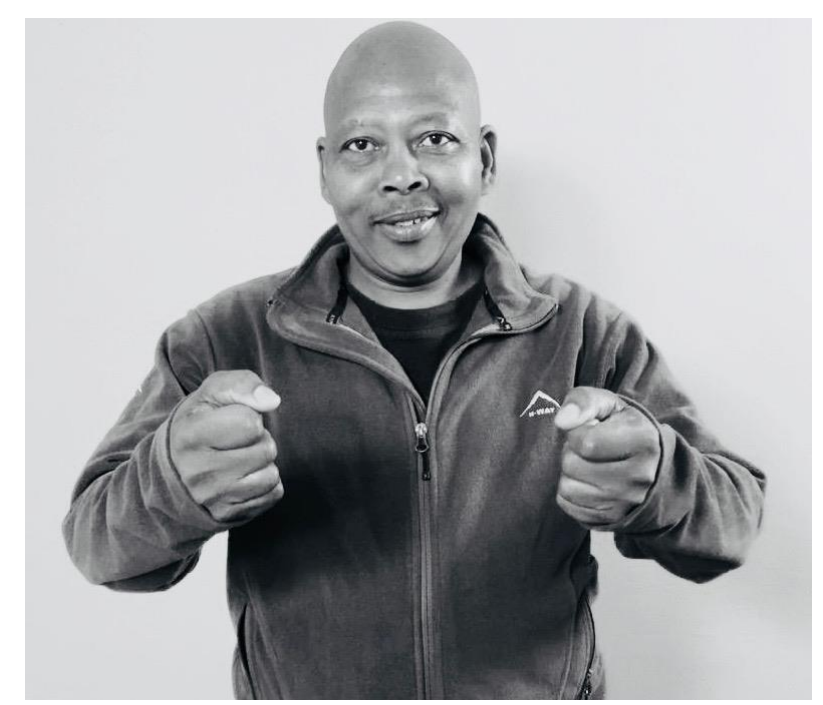

Figure 4. SASL lexical sign TO-DRIVE

The signed language used in South Africa, as indicated earlier, is SASL. According to the Deaf Federation of South Africa (DeafSA), approximately 1.5 million South Africans use a signed 
language in their daily lives, of whom the vast majority are deaf. SASL is not (yet) one of the official languages of South Africa. However, the Constitution of the Republic of South Africa proclaims "Sign Language" to be one of the languages of South Africa that must be promoted, and states that adequate conditions for its ongoing development and use must be created.

In the past, it was claimed that different Deaf communities across South Africa had their own sign language variants, resulting in 11 main SASL variants (Penn 1992-1994). Today, the emphasis is on the similarities between these variants, and DeafSA as well as other official institutions and organisations talk about one South African Sign Language. Although regional and other types of variation do exist - as is the case in many, if not all, signed (and spoken) languages - South African deaf people seem to manage very well in communicating across racial and geographical boundaries (Akach, Demey, Matabane, Van Herreweghe and Vermeerbergen 2009).

\section{Modus operandi}

\subsection{Translation standards for the South African Sign Language Bible Translation Project}

As already mentioned, signed languages do not have established written forms, but it is possible to video-record signed content and produce what is known as "signing books". Early signed texts or books were stored on videotapes, CD Roms, or on DVDs. More recently, videotaped content is mostly digitised and made available on the internet (Heyerick and Vermeerbergen 2011). A number of international organisations make use of widespread video and internet access to provide signed language Bible resources. Examples are DOOR International (doorinternational.org), who began work in 2006 on signed language Bible translations in Africa and South Asia, and the more recently founded Deaf Bible Society (DBS; www.deafbiblesociety.com). Many of these international organisations are members of the Forum of Bible Agencies International (FOBAI; forum-intl.org).

The DBS publishes Bible content in different signed languages on their Deaf Bible platform to make it freely available to Deaf communities. The South African Bible translation too is published by DBS. As DBS is a member of FOBAI, the society adheres to the FOBAI principles as expressed in the "Statement on Qualifications for Translation Consultants" (FOBAI 2006) and the more recent "Basic Principles and Procedures for Bible Translations" (FOBAI 2017). This implies (amongst other things) that the translations done by the SASL Bible translation team have to be approved by a translation consultant trained and provided by organisations such as DOOR International or SIL International (www.sil.org).

According to the DBS, signed language Bibles typically come in two versions: Chronological Bible Translation (CBT) structures Bible content by stories, whereas a Book-by-Book (BBB) sign language Bible is structured by the traditional chapter and verse breaks of the written version. The South African Sign Language Bible Project team decided on a CBT approach. On the DOOR website, CBT is explained as follows:

Deaf people best understand the Gospel when a Deaf believer shares it with them in the local sign language. Furthermore, Deaf people prefer to learn new information in a chronological order. They like to "see the big picture" from beginning to end. That's why our Deaf staff chose Chronological Bible Translation as the most culturally 
appropriate way to communicate God's Word with Deaf communities. We've found CBT to be a very clear, accurate, and natural way to teach unreached Deaf people about God. Because Deaf people can easily understand God's Word when it is in narrative form, they are able to go and teach it to others.

(https://doorinternational.org/what-we-do)

Each $\mathrm{CBT}^{6}$ consists of 110 biblical narratives from Genesis to Revelation. The 110 narratives are divided into three overlapping sets:

(i) Evangelism (“KNOW GOD HOW?”) - 32 narratives from Genesis 1 through Acts 2. These narratives give an overall picture to someone who has not heard or has heard very little about God;

(ii) Discipleship ("FOLLOW GOD HOW?") - 77 narratives from Genesis 1 through Acts 2. This is about how to follow God. Once the reader knows who God is, they learn how to follow Him; and

(iii) Church Planting (“SERVE GOD HOW?”) - 35 narratives from Acts 1 through Revelation.

The three sets together form an important part of the Bible but not the whole Bible. For example, set 1 constitutes approximately $3 \%$ of the Bible. When set 2 is added, then $6 \%$ of the Bible has been translated. Each narrative is accompanied by an introduction to provide context, and a section giving more information about the passage. ${ }^{7}$

\subsection{A sequence of 10 different steps}

The translation process for the SASL Bible translation project can be described as a subsequence of different steps: ${ }^{8}$

\section{Step 1: Reading and re-reading the English source text( $s$ )}

The team of three Deaf translators reads the text in English. They mainly use the English Standard Version of the Bible, although they sometimes also consult other English translations, e.g. to check if they understand something correctly. The ESV was published in 2001 by Crossway; it is a revision of the Revised Standard Version that employs an essentially literal translation approach (ESV 2001: ix). It was decided that it is best to (try and) stick to one translation, as different translations may have different aims. After having read the text, the three Deaf translators usually have questions, e.g. about the timeframe in which the story fits, or about certain concepts.

\footnotetext{
${ }^{6}$ Sometimes a distinction is made between Chronological Bible Stories (CBS) and Chronological Bible Translation (CBT). Roughly speaking, the difference is that with CBS there is some leeway in how the target text is structured, as long as the information of the story is there. This means that it is possible to leave certain verses out or add a verse from another chapter if that "makes the story flow better", as one of the project collaborators put it. CBT poses more challenges because every verse has to be translated accurately. It is permitted, however, to change the order of the verses when deemed necessary, due to the difference in structuring a signed story.

${ }^{7}$ This is called "Q\&A" in the SASL Bible Translation; on the Deaf Bible Society app, it is referred to as "More info".

${ }^{8}$ The process described here is mostly inspired by DOOR International and refined whilst working with a SIL translation consultant.
} 


\section{Step 2: Understanding the meaning of the source text}

This is where the exegetical assistant (EA), Banie Van der Walt, has an important role. ${ }^{9}$ He has the knowledge of Hebrew and Greek, the source languages, and has had thorough theological training. So, together with the EA, the team of three translators checks to see if they understand everything correctly. These conversations are interpreted by the signed language interpreter, Ananda Van der Walt. ${ }^{10}$ When the team is certain they understand everything, they go to the storyboard.

\section{Step 3: Drawing a storyboard}

Matthew Manake, one of the Deaf team members, then produces a storyboard consisting of drawings. This is basically the team's first concept translation. Matthew draws the story on several small pieces of paper. The drawings include all the information the translators need in order to visualise what they will sign. Matthew draws the story verse by verse and each picture is numbered in a certain way showing which verse it refers to. Some of the issues that were discussed in Step 2 (e.g. how to visualise and sign a specific concept or idea) are included in the drawings. The drawings are then placed in chronological order. This is done by the three Deaf team members. In this activity, the order of the verses may be altered. For example, in the story of Jesus going to the Sea of Galilee to talk to the people, it first says that Jesus went to the people and spoke to them, and only in verses 3 or 4 is the information provided about the time of this event. In a signed language narrative, it is typical to first sign the information on the time of the event, and then sign about the actual event; the order of the verses is therefore changed here. We should point out that the order of the information might be changed, but that all the information is still included.

\section{Step 4: Rehearsing the translation}

It is then decided who will sign the story on camera and that person will start practising. This entails memorising the story using the storyboard, first signing it picture by picture until s/he is able to sign the full story. While rehearsing, the other team members will be there to check, for instance, if all of the information is included, if all is clear, etc.

\section{Step 5: Filming the first video-recording}

The story is then recorded for the first time. This is done in a dedicated recording room (see Figures 5 and 6).

\footnotetext{
${ }^{9}$ Banie Van der Walt is the "assistant", not the "consultant". He has not been trained by DOOR or any other organisation qualified to delegate exegetical or translation consultants.

${ }^{10}$ More recently, the project team has been joined by another team of EAs as well as another SASL interpreter.
} 


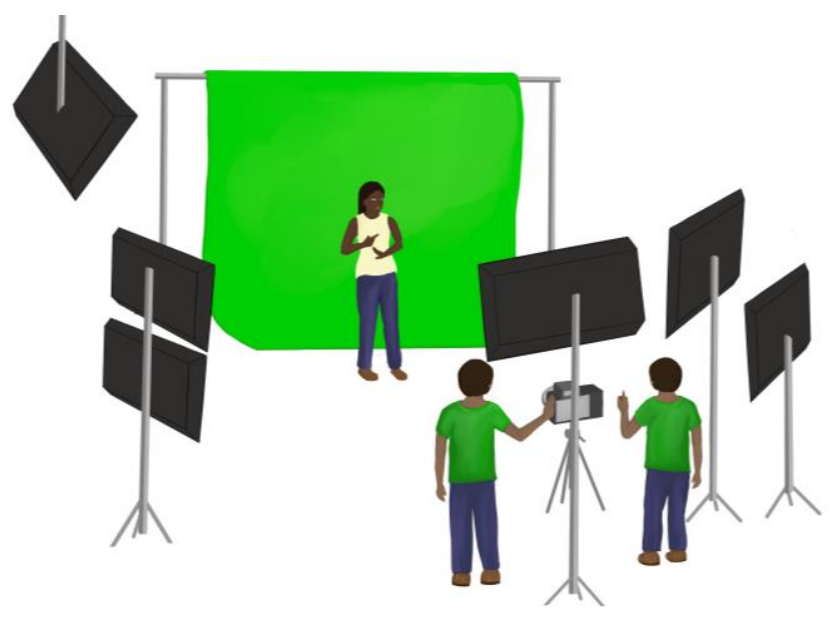

Figure 5. The recording studio set-up

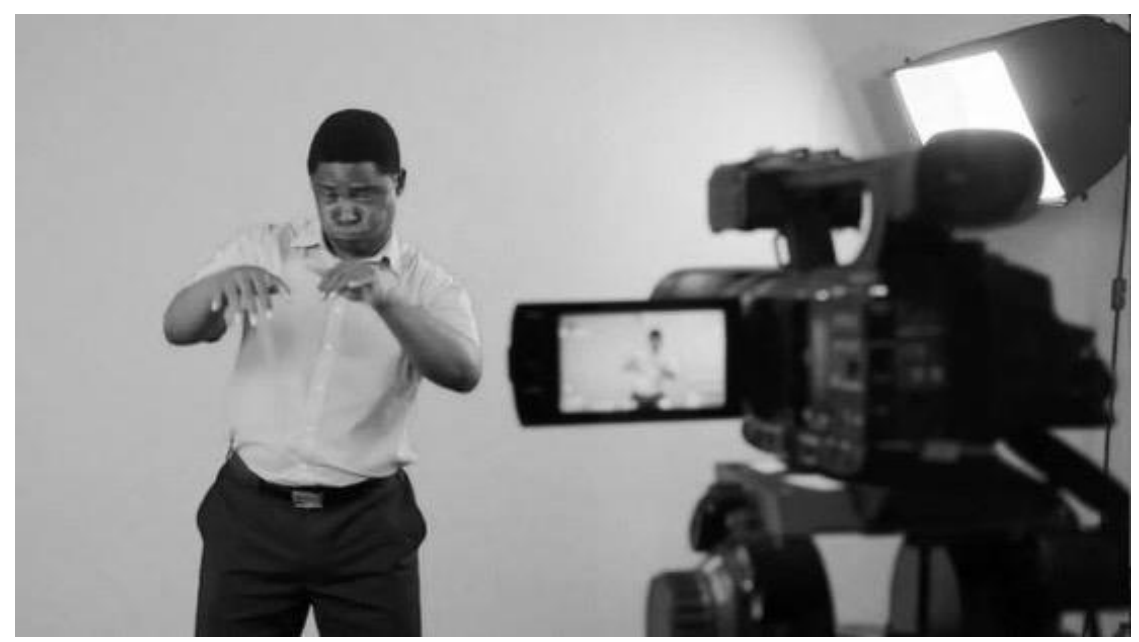

Figure 6. Recording in progress

Each story has an introduction and a Q\&A. In the introduction, background information is provided, for example, on where the story fits in and on what the previous story was. New name signs for places and people and new signs for concepts that do not yet have a sign in SASL are also introduced (see section 4). The signer wears a specific colour when signing the introduction, a different colour for the actual story, and yet another colour when signing the Q\&A, as an aid to the viewer.

One of the other two Deaf people handles the camera, and the third person is often also present to check if all of the information is there, whether the use of the signing space is correct, if everything is clear, whether facial expressions are accurate, etc. So if the signer makes a mistake, the others are able to tell him/her and the recording can be stopped immediately. When the recording is finished and the team is happy with it, it is uploaded onto a computer.

\section{Step 6: Check by the exegetical assistant}

After the recording has been uploaded, the Deaf team usually gives it back to Banie Van der Walt or another EA. The EA checks the recording for accuracy. In order to do this, ELAN is used - a software tool developed by the Max Planck Institute for Psycholinguistics in Nijmegen 
(Crasborn and Sloetjes 2008). ELAN allows video files to be imported and annotated. ${ }^{11}$ The annotations can be created on multiple tiers and time-aligned to the imported media. In this project, annotations consist mainly of glosses for signs, back translations, and comments.

Sometimes it only becomes clear from the way a certain meaning or concept is signed that the translator had not properly understood the original meaning or concept. This is often due to a misunderstanding of the English source text. By way of an example: in the translation of the English phrase "as far as" in "he went as far as the Dead Sea", the signer used the sign FAR and located the Dead Sea in order to express the meaning, "the Dead Sea was far". The EA picked this up. He explained that actually it was only a short distance, and that the meaning is "from that point to the Dead Sea" rather than the Dead Sea being far. It is mistakes like this that should be identified in this step.

\section{Step 7: Correcting mistakes}

Following the identification of the mistakes, the EA and the team discuss the mistakes and/or things that are missing. The EA may ask the team questions about certain parts to see if they have indeed understood correctly and/or he explains why something is wrong. After this, there is another recording session to correct the mistakes. Only the parts that were incorrect are recorded again and inserted into the full recording. This is then checked again by the EA and, if necessary, additional corrections are made and inserted. In this step, the translation goes back and forth between the team of translators and the EA - a process that requires regular conversations and discussions - until everyone is satisfied that that draft is as far as the team can take it. It is then saved for future Formal Community Testing (Step 8).

In the beginning of the project, back translations were done, also using ELAN. This required someone who understood the SASL translations and who would add glosses for the SASL signs and then insert the English back translation in ELAN. This was a very slow process and it was decided, in consultation with the translation consultants, that this was not necessary provided that there was the possibility to sit with the team of translators to discuss mistakes and passages that may not be clear (enough).

During the first couple of years, the SASL interpreter would sit with the EA to assist in the process of evaluating the draft translation. Now, the EA is able to understand SASL in context well enough to do most of the work on his own, although, in case of doubt, the interpreter is there to assist.

\section{Step 8: Formal Community Testing}

When there are enough stories ready for community testing - i.e. about 400 verses or 15 stories with their respective introductions and Q\&A parts - three to four representatives from the Deaf community across South Africa are invited to come to the Hands with Words office in Kenilworth, Cape Town (www.handswithwords.org.za) to view the stories. This step is called

\footnotetext{
${ }^{11}$ Between the time of writing the first version and the current final revision of the paper (May 2021), three important changes were implemented: (i) the team is now experimenting with an alternative programme, similar to ELAN but said to be more Deaf-friendly. However, this is still in the testing phases; (ii) due to the COVID-19 pandemic and the resulting lockdown, the Formal Community Testing (see Step 8) is now organised remotely using Zoom video-conferencing software which allows Deaf community members to participate remotely. This is done once a week; (iii) The project team is joined by a Deaf editor with excellent skills in video technology.
} 
"Formal Community Testing" (FCT). During FCT, the invited members of the Deaf community check to see if the signing is natural, and whether they understand the content and the meaning. They are not asked to check for accuracy as that is the task of the EA (see Step 7) and of the consultant (see Step 9). This testing lasts for one to two weeks. We discovered that three weeks is too long as the work done is very intense.

If possible, the translation consultant (see Step 9) is also present during FCT to give his/her feedback. It is then also possible for the consultant to engage with the representatives of the Deaf community. S/he will ask questions that allow him/her to decide if the message was clear and the story properly understood. As some biblical concepts are difficult to understand, it is important to identify the cause of any misunderstanding; is it because the signing is not clear or is it "simply" because it is a difficult concept, i.e. a concept that most hearing people reading the English Bible also do not understand? An example is "Son of Man", which is not "Son of God". It refers to the same person, i.e. Jesus as the Son of God, but "Son of Man" is a different reference. As there is a reason for this difference, it was necessary to create a separate sign. That reference had to be as vague as the related written text. In this specific case, it became clear that the signing was understood but the concept itself was not. This is not a problem that needs to be solved in the translation because it is a difficult concept. Sometimes a piece of the translation is not understood because the signing is not clear. Then the team will explain what it is supposed to say and the Deaf community will provide ideas of how to sign it more naturally and/or in a way that can be better understood.

Based on the feedback from the community and, ideally, the feedback from the consultant, changes are made to the recordings. When that is done, and double-checked by the EA to see if nothing has been left out and that all is clear and correct (i.e. repeating Steps 5 to 7 several times), then what is considered the "final draft" is produced.

\section{Step 9: Producing the "final draft"}

The draft video that is the final product of Step 8 is now used as a cue, i.e. it is displayed on several monitors in the recording room for the signer to consult. These monitors function as teleprompters in that they show a previous version of the story. The signer stands in front of the camera and uses the teleprompters while signing the final version. ${ }^{12}$ This implies that the signing from the cue is copied and the end result is a recording without cuts and inserted pieces, etc. If the story is too long to be signed in one single piece, the signer signs it in different sections.

This final draft is then checked by the EA and is subsequently given or sent to the Bible translation consultant for the final check (see Step 10).

\section{Step 10: Final check and "signing off"}

A trained translation consultant from overseas is responsible for "signing off" on the translation, confirming that it is correct, accepted by the Deaf community, and ready to be distributed. If possible, the consultant travels to South Africa to do the final check. However, this is not always possible, and sometimes recordings need to be sent to the consultant. In that case, the consultant may ask for back translations (an additional Step 11) because s/he does not know SASL. In

\footnotetext{
${ }^{12}$ As shown in Figure 5, there is not one but several monitors. This is because, during signing, the signer's eyegaze varies. By using multiple monitors/teleprompters, the signer has the option to change the direction of his/her gaze and still see (one of) the teleprompter(s).
} 
order for the consultant to make sure that $\mathrm{s} / \mathrm{he}$ understands everything that $\mathrm{s} / \mathrm{he}$ is seeing, $\mathrm{s} / \mathrm{he}$ may need to see an English rendering of the signed language.

When the final draft is approved, the very final version is produced. Here, the editor adds the background pictures and slots bigger sections together where the team divided very long translations into blocks.

As previously mentioned, the first set of stories - the 32 Evangelism stories - was published in April 2019. However, in the past seven years of working on the project, a total of 77 stories have been translated. The 45 additional stories are "the stories in between" the 32 that make up the first set. Currently, these 45 additional stories are being finalised before the team moves on and starts working on new stories.

\subsection{Important changes to the initial modus operandi}

It is evident that there have been changes to the modus operandi over the course of the past years. Here we discuss two of the major changes.

The first important change concerns the way the initial video-recorded draft translations are converted into their final form and how corrections are made to the video-recording during this process. Correcting mistakes in a video-recorded signed translation is not as straightforward as with a written translation, where replacing a word or phrase is easy. With a written text, if there is a certain word that needs replacing, this can be done using the software's "find and replace" function. In a video-recorded signed text, it is not possible to simply "cut out" a certain incorrect sign. Changing a mistake often requires the replacement of a rather long section. Initially, a final product level of quality was maintained throughout the process. This meant that each change that had to be done was to be made using the correct resolution and recorded sections had to stretch from one natural pause (e.g. where the signer would lower his/her hands) to the next natural pause. This made the process very slow as larger sections had to be recorded every time and often a new mistake was made while fixing an old one. Also, only a highly skilled editor could remove the old section and slot in the new. In the first years of the project, there was no full-time editor working on the project. Instead, a freelance (hearing) editor was brought in when needed. ${ }^{13}$ Due to the cost involved in this, such work had to be grouped together in order to make it worthwhile for both the editor and the organisation. This has led to very elaborate record holding in order to keep track of (i) which fixes (edits) had been done, (ii) which fixes had been re-checked for mistakes, (iii) which fixes were already slotted in, and (iv) which slotted-in drafts had been re-checked. All of this was to make sure the editor did not take out the wrong section or slot the new one in at the wrong place (seeing that the editor/s did not understand SASL or know the translations).

After the first Formal Community Testing, we decided to abandon this approach and make as small an edit as possible - sometimes only one sign - and slot it into a new draft using less professional software so it could be done by the team onsite and in real time. In this way, changes could be made, checked, and inserted in a short span of time, meaning it was fresh in everyone's minds and therefore easier to pick up mistakes and check the accuracy. Once a rough draft is approved by the consultant and some of the more difficult concepts checked again by members

\footnotetext{
13 The hearing freelance editor did not know SASL and needed assistance from the Deaf project manager or from an interpreter. A Deaf editor has recently joined the team.
} 
of the Deaf community, the rough draft is used as a cue and a final draft is recorded, with the resolution and lighting, etc. on standard (Step 9). This means that the team does not constantly have to memorise large sections of the translations and sign them over and over again. Only when the very final version has been recorded is the editor involved to add the background pictures and slot bigger sections together where the team divided very long translations into blocks.

A second important change relates to going back to the original Hebrew and Greek Bible stories. Initially, the EA (at that time the only one, now one of a team of three EAs) only started referring back to the original languages once the FCT process had shown that certain information could be or was misunderstood by all parties involved. A simple example is the misunderstanding due to the use of the English "you" to refer to both singular and plural persons. Genesis 20:7 states "he will pray for you and you shall live". From reading the text in the English Standard Version and looking at the immediate textual context, it is possible that God means that all the people, Abimelech included, will live. However, when the Hebrew of the specific section is parsed, it becomes clear that only Abimelech was meant. Therefore, even when the context in the English version seems to indicate one translation, the Hebrew source text can prove otherwise (see section 4 for a related example). Another interesting example involves the use of an incorrect facial expression. In the story about Noah and the flood, it is said that God told Noah that he was going to wipe the people off the earth because they were wicked and evil. This was signed by the Deaf translator with a facial expression showing anger. When the consultant did a final check, he realised that the facial expression was incorrect, as the Hebrew words to describe the action show that God's emotion was not one of anger, but closer to sadness. This had to be changed; not the manual part of the signing, as that was correct, but the accompanying facial expression.

It was soon realised that obvious mistakes could be avoided if the EA did a more in-depth study of the text and discussed that with the team while the translation was still in the storyboard phase (Step 3). Over time, in part related to his growing understanding of and proficiency in SASL, the main EA became better at identifying possible stumbling blocks beforehand and pointing them out to the team so that adjustments and corrections could be made while still in the storyboard phase.

\section{Challenges}

Obviously, producing a video-recorded Bible translation in a signed language is a massive project with many challenges. Some of the challenges are of a more practical or organisational nature. For example, the minimum requirements, as stated in a draft document by FOBAI and accepted by this project as a basis, are that a translation consultant from any of the member organisations such as SIL, United Bible Societies, and DOOR that will assist a translation team should, next to that organisation's own requirements, also be fluent in one major signed language. Internal requirements for translation consultants usually include a good working knowledge of biblical Hebrew and Greek as well as being familiar with Bible translation in general and the ability to work with people from different language groups. Obviously, there is only a handful of people worldwide who meet these requirements. In 2015, a first round of FCT was done in collaboration with a consultant from Japan. Unfortunately, when all the required changes resulting from that testing were implemented, the consultant was no longer available and it took over a year before another consultant was assigned to the project. This second consultant only committed to work with the team up until the finalisation of set 1 , meaning that a third consultant would need to be brought in for set 2 , and possibly yet another for set 3 . Other challenges relate to the fact that none of the Deaf team members are professionally trained 
signed language interpreters/translators and to the limited SASL proficiency level of the EA(s). In the remainder of this section, we will focus on those challenges that are connected to working between the written form of a spoken language (English) and a visual-gestural language with no written form and only a short history of institutionalisation (SASL).

A first major challenge relates to lexical gaps. Most of the signed languages that have been studied to date appear to have limited established lexicons, especially when they are compared to majority spoken languages such as English (Johnston 2012; Major, Napier, Ferrara and Johnston 2012). This is probably related in part to the importance of the productive lexicon, but also to the limited societal role of signed languages, e.g. in deaf education. For many years, signed languages have not been used as languages of teaching and learning, and signers have not been able to access tertiary education. As a result, many specialised concepts do not have an established sign. Not surprisingly, the biblical/theological lexicon of SASL is also underdeveloped. While signers often have strategies to compensate for lexical gaps - e.g. the use of fingerspelling, the productive constructions, pointing and gesturing, and the use of mouthings - it was felt that for the sake of a SASL Bible translation, it was best to avoid such strategies, especially those relying on (knowledge of) a spoken/written language. Fingerspelling, for example, involves representing the letters of written words from an oral language by using only the hands (or one single hand). This implies an adequate level of literacy in the language the words are borrowed from. Furthermore, using fingerspelling would mean choosing one language from the many spoken languages used in South Africa.

In many Deaf communities, fingerspelling is used to spell the names of people and places, especially when there is no name sign. A name sign is a specific sign used to refer to a specific person or place, and is usually independent of the given (spoken) name of a person. This means that two people with the same name - say, Peter - will most probably be assigned a different name sign. Many name signs are motivated: they are based on a unique and/or distinctive characteristic of a person, such as a characteristic of physical appearance, a typical body movement, or another personal habit. A person's profession may also inspire a name sign. Some name signs are related to the sound or the meaning of the spoken name of a person, e.g. a girl named Rose may get the sign ROSE as her name sign.

Many names of persons or places in the Bible have not yet received a name sign in SASL. Before creating a new name sign, the Deaf team members always consulted the broader Deaf community to ask for assistance. However, many name signs had to be created. For some of the names in the Bible, the EA was able to determine what the name meant or conveyed in the original languages. Hebrew names, for example, may have a specific meaning or resemble one or several words with a specific meaning. One of the sons of Abraham is called Ismael, which means "God will hear". His name sign "shows" a capped hand moving from near the ear away from the head. As there is a correlation between his brother's name, Isaac, and the Hebrew word "to laugh", the name sign for Isaac is based on the SASL sign TO-LAUGH. However, most name signs that were created are based on a description, action, or experience of a person as evident from the story. As Jacob was hit and hurt on the hip by an angel, his name sign refers to an injury to the hip (see Figure 7). 


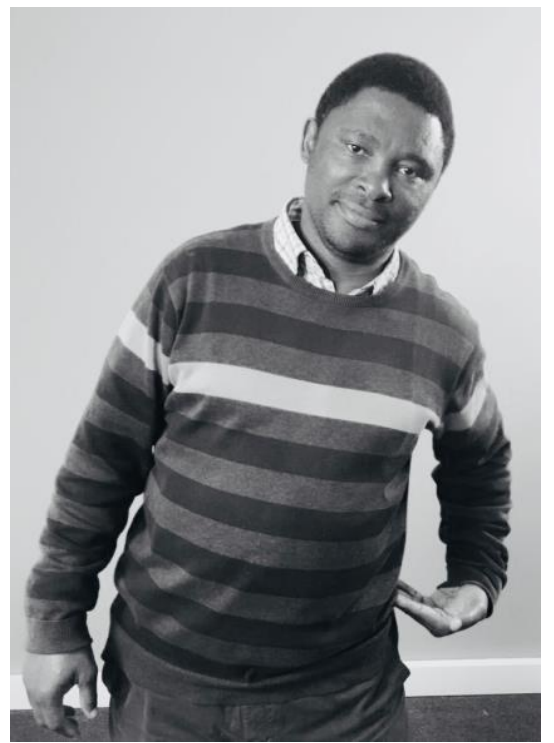

Figure 7. Name sign for Jacob

Most English translations of the Bible translate the Greek word kurios ('master') in the New Testament to "Lord" in lower case letters. When the capitalised LORD is used in the Old Testament, this is the translation of the Hebrew word Yahweh - the God of the Covenant. Although in both cases the referent is God, it is important to distinguish between the two as their meaning is different. It was decided to use the already existing SASL sign LORD to refer to "Lord" in the New Testament and to create a new sign to refer to "Lord of the Covenant" in the Old Testament. This newly created sign is a compound combining the letter $\mathrm{Y}$, the letter $\mathrm{H}^{14}$, and the sign GOD, referring to the Lord as "Yahweh", the Lord of the Covenant. It was decided that it is important to be very specific: if the original text says "LORD", it is not desirable to use the sign for "God", although the referent is the same. This was only brought up and discussed when most of the stories of set 1 had been translated. The team then had to go back and correct the instances where the sign GOD was used instead of the newly created sign referring to "Yahweh". While doing this, an additional and related issue arose. As explained in section 2, signers may establish a locus for a referent and pointing towards the locus may be used for future reference. There appeared to be instances where the team had first introduced the referent "Yahweh" by using a lexical sign and had subsequently localised the referent high in the signing space (see Figure 8). Pointing at a locus high in the signing space looks very similar to the SASL established sign GOD, although the non-manual features are different (see Figure 9).

\footnotetext{
${ }^{14}$ To avoid misunderstanding, we would like to stress here that, although sometimes individual (manual) letters from the manual alphabet used in the South African Deaf community are used in compound signs, the use of fingerspelling to represent whole words or names is avoided.
} 


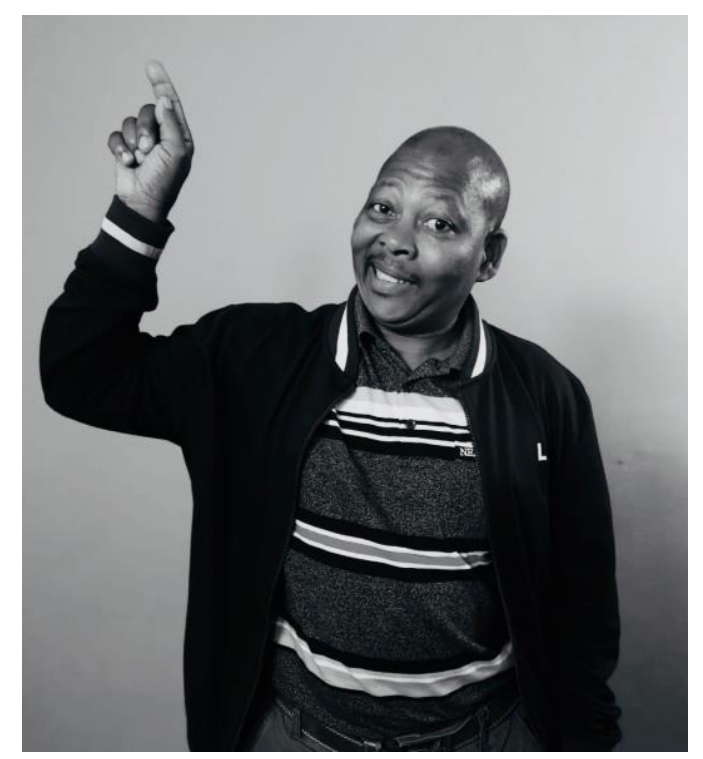

Figure 8. Pointing sign directed at a locus for "Yahweh"

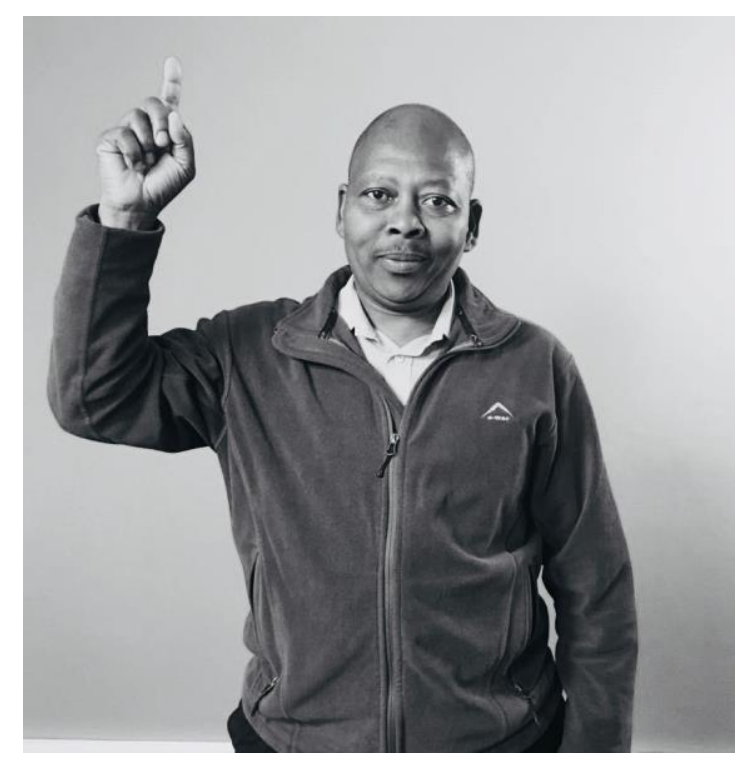

Figure 9. SASL sign for GOD

When this became clear, the team had to go back and double-check whether a clear distinction had been made between the pointing sign referring to a locus for "Yahweh" and the sign GOD.

For some lexical gaps, the team originally decided to use a phrase describing the concept. For the English word "temple", for example, the phrase BUILDING JEWS WORSHIP THERE was suggested. However, during the FCT (Step 8 of the process as presented in section 3), it became clear that most deaf participants misunderstood the sign. They understood this as "(the/some) Jewish people now (i.e. at this point in the story) go to (a building to) worship". In other words, the phrase was understood to be a verb phrase rather than a single nominal phrase referring to a specific type of building. The phrase was then replaced by a single sign, illustrated in Figure 10. 


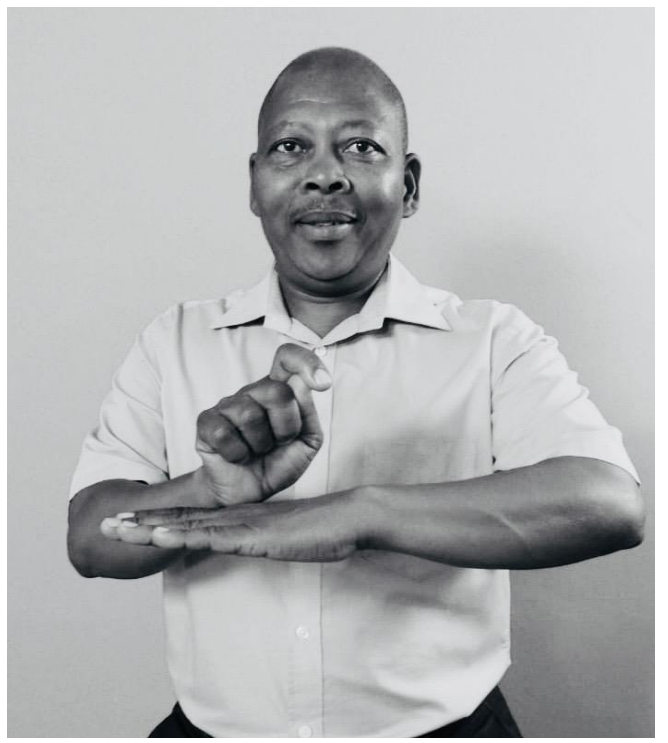

Figure 10. Sign used to translate the English word "temple"

It is of course important that the users of the Bible translation familiarise themselves with the newly created signs and name signs. These are therefore presented in an introduction accompanying every story.

A further challenge related to the specifics of the lexicon of signed languages is seen when signers use the productive lexicon to "show" rather than "simply tell" (see section 2). As mentioned earlier, using the productive lexicon, information about what an object looks like, the manner in which it moves or is moved, how it is handled, etc. is often overtly coded whereas this information is not always expressed in the (written) English Bible. An example to illustrate this relates to the fifteenth chapter of Genesis. This chapter reiterates the covenant God had made with Abraham at the latter's calling. In Genesis 15:9-10, God asks Abraham to find and kill a heifer, a ram, a goat, a dove, and a pigeon. Abraham then cut the first three animals in half and lay the pieces in two rows, leaving a path through the centre. Working on the translation, the team felt it was necessary to know how the animals were cut in half: horizontally, so that there would be a front and back, or vertically, so that they were divided in left and right parts. However, this information is not included in the English Bible, and is also not available in the Hebrew text. It is very possible that this lack of detail is because it was (relatively) common knowledge at the time of writing. What is described here is a ritual that was done in ancient Near Eastern royal land grant treaties to seal the promises made (Myers 1987, Hamilton 1990). The importance of shared information and background knowledge for interpreters and translators will be discussed further in section 5 .

A final challenge with regard to the SASL lexicon concerns lexical variation. As already mentioned in section 2, the SASL dictionaries published in the first half of the 1990s suggest that there is considerable regional variation in the lexicon (Penn 1992-1994). This is confirmed by Van Niekerk's (2020) recent study based on a comparison of signs used by SASL learners from different schools across South Africa. The project team is aware of this regional variation. Given that research into and documentation of the existing regional variation is still very limited, especially with regard to the specialised lexicon used in this project, the translators need to rely mainly on their own knowledge and experiences, and on input and feedback from other members of the Deaf community. We note here that there is not only regional variation 
to take into account, but also the variation in educational background and signed language proficiency levels (Vermeerbergen 2007). The Deaf translators have extensive experience in communicating with SASL signers from very different backgrounds, and they often know which signs are more generally/widely used. When in doubt, they consult with a variety of deaf representatives from all provinces and from Deaf churches in South Africa. In some cases, signs were also discussed and negotiated during the FCT process (see Step 8), where it was then decided which signs would be best understood by the general Deaf audience.

Other challenges the team encountered do not relate to the lexicon of SASL but to differences between the grammar of the written English in the source text and the grammar of SASL. A simple example mentioned earlier is when "you" is used in English without specifying whether this is a second-person singular or a plural reference; SASL does require this difference to be expressed. In the beginning, the English word "you" was translated in SASL as singular, unless it was very clear from the context that the plural was implied. When it became clear that mistakes were being made, the team realised it was important to seek clarification whenever it was unclear whether the intended referent was singular or plural. This simple example shows the importance of assisting the team in grasping the full and exact meaning of the text.

In some instances, the EA was able to provide clarification based on the Hebrew text. An example comes from Exodus 20:26, where Yahweh gives prescriptions on how altars should be built. One of these prescriptions states that an altar may not be so high that a ladder is needed to reach the top, as this would cause the nakedness of the person climbing the ladder to be exposed "onto it". It is not at all clear from the English translation what this instance of "it" refers to. It could be the ladder, the altar, the people looking, or even Yahweh. Based on the fact that in Hebrew, pronouns agree with their antecedent in gender and number, it can be determined that this pronoun "it" refers to the altar. This can be left vague, as in the English translation, but the force of the prohibition is lost as the implication is that the altar is defiled if the priest's nakedness is exposed to it.

A last challenge specifically worth mentioning is the use of indirect speech in the written English and the identification of the person speaking. There were several cases where it became clear during the FCT that Deaf community members understood what was said but were not clear about who was saying it. This is especially the case when more than two people are involved or when God is having a conversation with more than one person. In such instances, localisation of referents and subsequent appropriate use of the loci assigned is of utmost importance. Translating a sentence such as (Abraham speaking to Abimelech) "And when God caused me to wander from my father's house, I said to her: "This is the kindness you must do me: at every place to which we come, say of me "He is my brother."" in a signed language can be very challenging. Here, Abraham is telling Abimelech that he (Abraham) told Sarah that she must tell people that he (Abraham) is her brother (Genesis 20:13). It took (and is still taking) the team some time to realise that it is permissible to recreate the original scene and use direct speech, even when indirect speech is used in the English text. It is fascinating to see the ease with which the team can explain to the community what is actually going on in a specific section and they understand instantly, while, when translating that same section, the team gets caught up in discussions about technicalities. 


\section{Translating as a process of meaning making}

Wilcox and Shaffer (2005), in their argument against the model of the interpreter as a "conduit", propose a cognitively oriented view of communication. They argue that, when communicating, it is not the case that the speaker or signer packs content into words or signs to be sent off and unpacked by the recipient, nor that the recipient - the listener, in the case of a spoken language, or the viewer, in the case of a signed language - has direct access to the speaker's or signer's (intended) meaning. According to Turner (1991: 206), "expressions do not mean; they are prompts for us to construct meaning". Such an approach to communication obviously has consequences for the way in which the process of interpreting is understood because interpreting is, at heart, about communicating. And consequently, as Janzen (2005: 7) writes:

the meaning of a source message is never directly accessible $[\ldots]$ and the interpreter cannot directly "convey" what is meant. [...] Interpreters do not directly convey a message but rather gather evidence of meaning and construct a new text. Depending on what the interpreter knows and what her skills are, this new text more or less approximates the original - a great deal when the process works well, and very little when it doesn't.

We believe this is not only true for signed language interpreters but also for signed language translators.

Translators too first "gather evidence of meaning" and then "construct a new text". The first step implies that the translator needs to interpret the cues that are presented by the written text. However, as Turner (1991: 206, in Wilcox and Shaffer 2005: 44) states, "in order to understand, we must bring to bear elaborate and detailed conceptual knowledge not referred to in the expression". Indeed, in order to piece together the meaning of a message or text, listeners, viewers, and readers not only rely on the linguistic form (the words, the grammar, the way a text is structured, etc.) but also on the intended effect of the text, as well as on their own experiences and knowledge. Obviously, it is much easier to construct the intended meaning when the message or text is about something known, talks about an environment that can be pictured, and/or features familiar people. For the team working on the SASL Bible translation, piecing together the meaning of the source texts is a huge and challenging task. Not only are the texts written in English, a language that is not their first language, the meaning making process also requires a great deal of background knowledge.

In Step 1, the linguistic form of the text is important as a resource for gathering meaning. In Step 2 as well, linguistic form is an important issue. Janzen (2005: 8) writes: "when the target text is being constructed, it is the interpreter's linguistic resources that will largely determine its structure, not the source speaker's or signer's". Again, Janzen is referring to signed language interpreters, but when we replace "interpreter" with "translator" and "source speaker's or signer's" with "source writer's", we believe this to be equally valid in the case of signed language translation.

As is the case with interpreting, in translation too the aim is that the "new text approximates the original a great deal". Whether or not this aim can be achieved depends "on what the interpreter - or translator - knows and what her skills are" (Janzen 2005: 7). In the South African Sign Language Bible Translation Project, knowledge and skills do not come from one single person but from a group of experts, each bringing their own skills and knowledge. 
As previously mentioned, the project team consists of three Deaf signers, working together with (i) EAs who have Biblical/theological knowledge as well as knowledge of the source languages Greek and Hebrew, (ii) a SASL interpreter who has excellent command of both English and SASL, and (iii) a Bible translation consultant with expertise in signed language (Bible) translations, also knowing the source languages and at least one signed language. The team, because of the combined knowledge and skills, is clearly a strong one, both when it comes to gathering evidence of meaning based on the original text as well as to creating a new text which approximates the original a great deal. However, additional expertise would be welcomed. More specifically, it is felt that the project would benefit from collaboration with or input from a scholar with (theoretical) knowledge of the linguistics of SASL or seeing that SASL is one of the understudied signed languages and knowledge about its linguistic structure is still rather scarce - with a strong expertise in general signed language linguistics. This person should preferably be a deaf native signer of SASL, i.e. someone who combines theoretical knowledge with native signer intuition.

In conclusion, the possibility to create signed content as an alternative for a written text, paper, or book, is a relatively new development. Over the past 10 to 15 years, technological developments have created many more possibilities to video-record and distribute signed messages and texts. Today, basic video-editing software comes standard with any hardware purchase, and even on smartphones there are now advanced features like colour correction, auto focusing, downscaling, and filter effects that were previously only available for post-production using specialist software (Leeson, Sheikh and Vermeerbergen 2015). But it is in using this technology that lie the challenges.

It is hoped that the near future will bring positive changes in deaf education, and that South African deaf people's chances of entering the tertiary education sector will improve. Then projects such as ours can benefit from the specialised knowledge and skills of educated/trained deaf linguists, translators, as well as video editors.

Finally, we would like to point out that, as the production of video-recorded signed translations of written texts is a relatively new phenomenon, much remains to be learned, and a project such as this one offers ample opportunities for research, e.g. on how end-users engage with the signed content and how they, in turn, become part of the process of meaning making.

\section{References}

Akach, P., E. Demey, E. Matabane, M. Van Herreweghe and M. Vermeerbergen. 2009. What is South African Sign Language? What is the South African Deaf community? In B. BrockUtne and I. Skattum (eds.) Languages and education in Africa: A comparative and transdisciplinary analysis. Bristol: Symposium Books. pp. 333-347. https://doi.org/10.15730/books.69

Baker, B. 1987. The Holy Bible: English version for the Deaf. Ada, MI: Baker Publishing Group.

Bible Society of South Africa. 2008. Die Bybel vir almal. $2^{\text {nd }}$ Edition. Bellville: Bible Society of South Africa. 
Brennan, M. 1990. Word formation in British Sign Language. Stockholm: University of Stockholm.

Brennan, M. 1992. The visual world of British Sign Language: An introduction. In D. Brien (ed.) Dictionary of British Sign Language/English. London: Faber and Faber. pp. 1-133.

Crasborn, O. and H. Sloetjes. 2008. Enhanced ELAN functionality for sign language corpora. In O. Crasborn, T. Hanke, E. Efthimiou, I. Zwitserlood and E.Thoutenhoofd (eds.) 3rd Workshop on the representation and processing of sign languages: Construction and exploitation of sign language corpora. Paris: ELRA. pp. 39-43. https://doi.org/10.1353/sls.0.0044

Cuxac, C. 2000. La langue des signes française: Les voies de l'iconicité. (Faits de langues, no. 15-16.) Paris: Ophrys.

Demey, E., M. Van Herreweghe and M. Vermeerbergen. 2008. Iconicity in sign languages. In K. Willems and L. De Cuypere (eds.) Naturalness and iconicity in linguistics. Amsterdam: Benjamins: 189-214. https://doi.org/10.1075/ill.7.11dem

Enfield, N.J. 2004. On linear segmentation and combinatorics in co-speech gesture: A symmetry-dominance construction in Lao fish trap descriptions. Semiotica 149: 57-123. https://doi.org/10.1515/semi.2004.038

Forum of Bible Agencies International. 2006. Statement on qualifications for translation consultants. Available online: https://forum-intl.org/resources/translation-standards/ (Accessed 30 August 2019).

Forum of Bible Agencies International. 2017. Basic principles and procedures for Bible translations. Available online: https://forum-intl.org/resources/translation-standards/ (Accessed 30 August 2019).

Geers, A. and H. Hayes. 2011. Reading, writing, and phonological processing skills of adolescents with 10 or more years of cochlear implant experience. Ear Hear 32(10): 49S-59S. https://doi.org/10.1097/aud.0b013e3181fa41fa

Glaser, M. and E. Van Pletzen. 2012. Inclusive education for deaf students: Literacy practices and South African Sign Language. Southern African Linguistics and Applied Language Studies 30(1): 25-37. https://doi.org/10.2989/16073614.2012.693707

Hamilton, V.P. 1990. The book of Genesis: Chapters 1-17. Grand Rapids, MI: William B. Eerdmans Publishing Company.

Heyerick, I. and M. Vermeerbergen. 2011. Documenting, analysing, involving and informing: The case of the research project on expressing plurality in Flemish Sign Language. Paper presented at the "Second Symposium in Applied Sign Linguistics", Centre for Deaf Studies, University of Bristol, Bristol. 
Hrastinski, I. and R.B. Wilbur. 2016. Academic achievement of deaf and hard-of-hearing students in an ASL/English bilingual program. The Journal of Deaf Studies and Deaf Education 21(2): 156-170. https://doi.org/10.1093/deafed/env072

Janzen, T. 2005. Introduction to the theory and practice of signed language interpreting. In T. Janzen (ed.) Topics in signed language interpreting: Theory and practice. Amsterdam/Philadelphia: John Benjamins. pp. 3-24. https://doi.org/10.1075/btl.63.04jan

Johnston, T. 2012. Lexical frequency in sign languages. Journal of Deaf Studies and Deaf Education 17(2): 163-193. https://doi.org/10.1093/deafed/enr036

Lederberg, A.R., B. Schick and P.E. Spencer. 2013. Language and literacy development of deaf and hard-of-hearing children: Successes and challenges. Developmental Psychology 49(1): 15-30. https://doi.org/10.1037/a0029558

Leeson, L., H. Sheikh and M. Vermeerbergen. 2015. The superhighway or the slow lane? Evaluating challenges in creating new learning spaces for interpreters. In S. Ehrlich and J. Napier (eds.) Interpreter education in the digital age: Innovation, access, and change. Washington, DC: Gallaudet University Press. pp. 153-198.

Liddell, S.K. and M. Metzger. 1998. Gesture in sign language discourse. Journal of Pragmatics 30(6): 657-697. https://doi.org/10.1016/s0378-2166(98)00061-7

Lombaard, S and J.A. Naudé. 2007. The translation of biblical texts into South African Sign Language. Southern African Linguistics and Applied Language Studies 25(2): 141-152. https://doi.org/10.2989/16073610709486453

Major, G., J. Napier, L. Ferrara and T. Johnston. 2012. Exploring lexical gaps in Australian Sign Language for the purposes of health communication. Communication \& Medicine 9(1): 37-47. https://doi.org/10.1558/cam.v9i1.37

Marshark M. 1997. Raising and educating a deaf child: A comprehensive guide to the choices, controversies, and decisions faced by parents and educators. New York: Oxford University Press.

Metzger, M. 1995. Constructed dialogue and constructed action in American Sign Language. In C. Lucas (ed.) Sociolinguistics in Deaf communities. Washington, DC: Gallaudet University Press. pp. 255-271. https://doi.org/10.1017/s0047404500019576

Mitchell, R.E. and M. Karchmer. 2004. Chasing the mythical ten percent: Parental hearing status of deaf and hard of hearing students in the United States. Sign Language Studies 4(2): 138-163. https://doi.org/10.1353/sls.2004.0005

Myers, A.C. 1987. The Eerdmans Bible dictionary. Grand Rapids, MI: Eerdmans.

Penn, C. 1992-1994. Dictionary of southern African signs for communicating with the Deaf. Volumes 1-5. Pretoria: Human Sciences Research Council and the South African National Council for the Deaf. 
Perniss, P., R. Pfau and M. Steinbach. 2007. Can't you see the difference? Sources of variation in sign language structure. In P. Perniss, R. Pfau and M. Steinbach (eds.) Visible variation: Comparative studies on sign language structure. Berlin: Mouton de Gruyter. pp. 1-34. https://doi.org/10.1515/9783110198850

Taub, S., P. Pinar and D. Galvan. 2002. Comparing spatial information in speech/gesture and signed language. Paper presented at the "Gesture: The Living Medium" conference. Austin, TX, 5-8 June 2002.

The Holy Bible. English Standard Version. 2001. Wheaton, IL: Crossway.

Turner, M. 1991. Reading minds: The study of English in the age of cognitive science. Princeton, NJ: Princeton University Press.

Van Niekerk, A. 2020. A Lexical Comparison of South African Sign Language and Potential Lexifier Languages. Unpublished Master's thesis, University of Stellenbosch.

Vermeerbergen, M. 2006. Past and current trends in sign language research. Language and Communication 26(2): 168-192. https://doi.org/10.1016/j.langcom.2005.10.004

Vermeerbergen, M. 2007. South African signers: Apples and pears and how they relate to each other. Paper presented at the joint annual meeting of the Linguistics Society of South Africa, the South African Applied Linguistics Association, and the South African Association for $\begin{array}{lllll}\text { Language } & \text { Teaching. } & \text { Potchefstroom, } & 4-6 & \text { July }\end{array}$ https://doi.org/10.1080/10118063.1985.9723725

Vermeerbergen, M. and E. Demey. 2007. Sign + Gesture = Speech + Gesture ? Comparing aspects of simultaneity in Flemish Sign Language to instances of concurrent speech and gesture. In M. Vermeerbergen, L. Leeson and O. Crasborn (eds.) Simultaneity in signed languages: Form and function. Amsterdam: John Benjamins. pp. 257-282. https://doi.org/10.1075/cilt.281.12ver

Vermeerbergen, M. and L. Leeson. 2011. European signed languages - Towards a typological snapshot. In B. Kortmann and J. van der Auwera (eds.) Field of linguistics: Europe. Berlin: Mouton de Gruyter. pp. 269-287. https://doi.org/10.1515/9783110220261.269

Vermeerbergen, M. and M. Van Herreweghe. 2010. Sign languages and sign language research. In J. Guendouzi, F. Loncke and M. Williams (eds.) The handbook of psycholinguistic and cognitive processes: Perspectives in communication disorders. London: Taylor \& Francis. pp. 707-727. https://doi.org/10.4324/9780203848005.ch34

Vermeerbergen, M., L. Leeson and O. Crasborn (eds.) 2007. Simultaneity in signed languages: Form and function. Amsterdam: John Benjamins. https://doi.org/10.1075/cilt.281

Wilcox, S. and B. Shaffer. 2005. Towards a cognitive model of interpreting. In T. Janzen (ed.) Topics in signed language interpreting: Theory and practice. Amsterdam/Philadelphia: John Benjamins. pp. 27-50. https://doi.org/10.1075/btl.63.06wil 